\title{
Compositional stability of FePt nanoparticles on SiO2/Si during annealing
}

Richard R. Vanfleet

rrv3@byu.edu

B. Yao

R. V. Petrova

K. R. Coffey

Follow this and additional works at: https://scholarsarchive.byu.edu/facpub

Part of the Astrophysics and Astronomy Commons, and the Physics Commons

\section{Original Publication Citation}

Yao, B., R. V. Petrova, R. R. Vanfleet, and K. R. Coffey."Compositional stability of FePt nanoparticles on SiO[sub 2]/Si during annealing." AIP, 26.

\section{BYU ScholarsArchive Citation}

Vanfleet, Richard R.; Yao, B.; Petrova, R. V.; and Coffey, K. R., "Compositional stability of FePt nanoparticles on SiO2/Si during annealing" (2006). Faculty Publications. 315.

https://scholarsarchive.byu.edu/facpub/315 


\title{
Compositional stability of FePt nanoparticles on $\mathrm{SiO}_{2} / \mathrm{Si}$ during annealing
}

\author{
B. $\mathrm{YaO}^{\mathrm{a})}$ \\ Advanced Materials Processing and Analysis Center and Department of Mechanical, Materials \\ and Aerospace Engineering, University of Central Florida, Orlando, Florida 32816 \\ R. V. Petrova \\ Department of Physics, University of Central Florida, Orlando, Florida 32816 \\ R. R. Vanfleet \\ Department of Physics and Astronomy, Brigham Young University, Provo, Utah 84602
}

K. R. Coffey

Advanced Materials Processing and Analysis Center, Department of Mechanical, Materials and Aerospace Engineering, and Department of Physics, University of Central Florida, Orlando, Florida 32816

(Presented on 1 November 2005; published online 25 April 2006)

The loss of Fe due to oxidation or diffusion into the substrate can prevent the successful preparation of well-ordered, stoichiometric, FePt nanoparticles. In this work we report the composition changes during annealing observed for small $(<10 \mathrm{~nm}) \mathrm{FePt}$ nanoparticles on thermally grown $\mathrm{SiO}_{2}$ layers on $\mathrm{Si}$ wafer substrates. Additionally, we describe the use of a controlled reducing gas mixture, $\mathrm{Ar}+\mathrm{H}_{2}+\mathrm{H}_{2} \mathrm{O}$, to reduce the loss of Fe. (c) 2006 American Institute of Physics.

[DOI: $10.1063 / 1.2170064]$

\section{INTRODUCTION}

FePt alloys consisting of the chemically ordered $L 1_{0}$ phase are of interest for ultrahigh magnetic recording media applications due to the high magnetocrystalline anisotropy $\left(\sim 10^{7}-10^{8} \mathrm{ergs} / \mathrm{cm}^{3}\right)$ of this tetragonal crystal structure. Typically, the synthesis of ordered $L 1_{0} \mathrm{FePt}$ nanoscale materials involves the preparation of A1 (fcc) phase FePt thin film or nanoparticle samples, and subsequent annealing to allow the fcc to $L 1_{0}$ phase transformation. During this process, control of the chemical stoichiometry should be maintained because of the strong dependence of the chemical order and uniaxial magnetic anisotropy on stoichiometry. ${ }^{1-4}$ However, few reports have been published on the compositional stability during annealing of FePt nanoscale samples. Thomson et al. reported the formation of $\mathrm{Fe}$ silicides due to the hightemperature annealing for FePt thin films on a Si substrate, which caused a substantial drop in magnetization. ${ }^{5}$ While thermally grown $\mathrm{SiO}_{2}$ layers are commonly used with $\mathrm{Si}$ wafer substrates to prevent silicide formation, quantitative reports on the effectiveness of the $\mathrm{SiO}_{2}$ layer to maintain sample stoichiometry are absent.

In this paper we report the compositional stability of FePt nanoparticles on $\mathrm{SiO}_{2} / \mathrm{Si}$ substrates during annealing in a reducing gas, consider possible mechanisms of Fe loss, and describe a controlled reducing gas annealing that improves compositional stability. Analytical transmission electron microscopy (TEM) was used to quantify the compositions of FePt nanoparticles prepared on thin $(31 \mathrm{~nm}) \mathrm{SiO}_{2}$ layers. A loss of Fe during annealing at $750{ }^{\circ} \mathrm{C}$ in $97 \% \mathrm{Ar}+3 \% \mathrm{H}_{2}$ was observed. The diffusion of $\mathrm{Fe}$ into the $\mathrm{SiO}_{2}$ layer and chemical reaction of $\mathrm{Fe}$ with the $\mathrm{SiO}_{2} / \mathrm{Si}$ substrate were considered to be likely mechanisms for the Fe loss. The diffu-

${ }^{a)}$ Electronic mail: bo555252@ pegasus.cc.ucf.edu sion of $\mathrm{Fe}$ across the thermally grown $\mathrm{SiO}_{2}$ layer was observed for a relatively thick $(8 \mathrm{~nm})$ FePt deposit on a thin $\mathrm{SiO}_{2}$ layer. Annealing with a controlled reducing gas mixture of $\mathrm{Ar}+\mathrm{H}_{2}+\mathrm{H}_{2} \mathrm{O}$ was explored to reduce the loss of Fe during annealing. In the presence of the uncontrolled trace levels of water vapor expected during annealing, a high $\mathrm{H}_{2}$ partial pressure can favor the formation of iron silicide, while a low $\mathrm{H}_{2}$ partial pressure may allow the formation of iron oxide. Based on simple thermodynamic considerations, a ratio of $\mathrm{H}_{2}$ partial pressure to that of $\mathrm{H}_{2} \mathrm{O}$ between 1.0 and 2.4 should be maintained for maximum stability of $\mathrm{FePt}$ in the presence of $\mathrm{SiO}_{2}$. FePt nanoparticles on thin $\mathrm{SiO}_{2}(31 \mathrm{~nm})$ have been so annealed and the stability of the stoichiometry confirmed by analytical TEM. We conclude that the loss of $\mathrm{Fe}$ into $\mathrm{SiO}_{2} / \mathrm{Si}$ is a concern for the compositional stability of single layers of FePt nanoparticles during hightemperature annealing and that control of the annealing gas ambient can significantly improve compositional stability.

\section{EXPERIMENT}

The $\mathrm{Fe}_{50} \mathrm{Pt}_{50}$ deposits were prepared at room temperature by $\mathrm{DC}$ co-sputtering of $\mathrm{Fe}$ and $\mathrm{Pt}$ from elemental targets. The initial deposit was not a continuous film, rather a collection of nanoparticles and/or a discontinuous thin film. The base pressure of the sputtering system was in the $10^{-8}$ Torr range prior to the introduction of the Ar sputtering gas at a pressure of 3 mTorr and a flow rate of 20 SCCM (standard cubic centimeter per minute). The amounts of FePt deposited corresponded to thicknesses of $0.25,2$, and $8 \mathrm{~nm}$. The $0.25-\mathrm{nm}$ - and 8-nm-thick films were deposited onto oxidized $\mathrm{Si}(100)$ wafers with an oxide thickness of $31 \mathrm{~nm}$, while that for 2-nm-thick film was more than $100 \mathrm{~nm}$. Film compositions were calibrated by Rutherford backscattering spectrometry (RBS). The uncertainties in elemental concentrations were \pm 0.5 at. \% for both the Fe and Pt. 

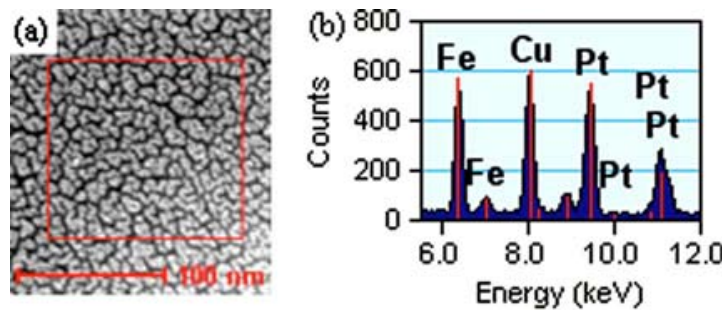

FIG. 1. TEM image and EDX spectrum of sample A. (a) HAADF image indicating region sampled and (b) EDX spectrum.

As is commonly done, ${ }^{6}$ FePt nanoparticle samples were annealed at atmospheric pressure with a reducing gas flow to prevent the film from oxidizing. In our experiments a reducing gas of $97 \% \mathrm{Ar}+3 \% \mathrm{H}_{2}$ was used for annealing of $750{ }^{\circ} \mathrm{C}$ for $20 \mathrm{~h}$. While some trace levels of water vapor are expected to be present, the $\mathrm{H}_{2} \mathrm{O}$ vapor pressure is not controlled and concentration in the gas flow is very low, and this procedure is referred to as an uncontrolled reducing gas annealing. For this annealing condition a loss of Fe can be observed for FePt nanoparticles, as described below.

Experiments using a more controlled reducing gas annealing condition were also performed. For these experiments, an intentionally higher and controlled $\mathrm{H}_{2} \mathrm{O}$ vapor pressure was used in conjunction with the $97 \% \mathrm{Ar}+3 \% \mathrm{H}_{2}$ reducing gas to reduce the possible formation of silicides, as well as oxides, during high-temperature annealing.

A thermodynamic model of the chemical reactions of $\mathrm{Fe}$, $\mathrm{Si}, \mathrm{H}$, and $\mathrm{O}$ is described below to illustrate the advantages of a controlled reducing gas annealing for FePt nanoparticle processing. This very simplified model assumes that the $\mathrm{Pt}$ does not participate, that the Fe present is available as elemental $\mathrm{Fe}$, that the available bulk thermodynamic data are representative of thin films, and that mixtures (e.g., $\left.\mathrm{Si}_{1} \mathrm{Fe}_{x} \mathrm{O}_{y}\right)$ and other phases do not form. The reactions that are considered are the formation of an iron silicide with the reduction of $\mathrm{SiO}_{2}$, Eqs. (1) and (2), and the formation of iron oxide by reaction with water vapor, Eq. (3). Qualitatively, in a strongly reducing ambient, the reduction of $\mathrm{SiO}_{2}$ makes $\mathrm{Si}$ available and promotes the formation of $\mathrm{FeSi}$, while in a nonreducing ambient water vapor is able to oxidize Fe and form $\mathrm{FeO}$.

$$
\begin{aligned}
& \mathrm{Fe}+\mathrm{SiO}_{2}+2 \mathrm{H}_{2} \leftrightarrow \mathrm{FeSi}+2 \mathrm{H}_{2} \mathrm{O} \\
& \mathrm{Fe}+2 \mathrm{SiO}_{2}+4 \mathrm{H}_{2} \leftrightarrow \mathrm{FeSi}_{2}+4 \mathrm{H}_{2} \mathrm{O}
\end{aligned}
$$

\begin{tabular}{|c|c|c|c|c|c|}
\hline & \multirow[b]{2}{*}{$\begin{array}{l}\text { Nominal FePt } \\
\text { thickness }(\mathrm{nm})\end{array}$} & \multirow{2}{*}{$\begin{array}{l}\mathrm{SiO}_{2} \\
\text { thickness } \\
\quad(\mathrm{nm})\end{array}$} & \multicolumn{3}{|c|}{ Annealing condition } \\
\hline & & & $\begin{array}{l}\text { Temperature } \\
\left({ }^{\circ} \mathrm{C}\right)\end{array}$ & $\begin{array}{l}\text { Time } \\
\text { (h) }\end{array}$ & Gas \\
\hline Sample A & 4 & 31 & N/A & N/A & N/A \\
\hline Sample B & 0.25 & 31 & 750 & 20 & $\mathrm{Ar} / \mathrm{H}_{2}$ \\
\hline Sample C & 0.25 & 31 & 750 & 20 & $\mathrm{Ar} / \mathrm{H}_{2} / \mathrm{H}_{2} \mathrm{O}$ \\
\hline Sample D & 8 & 31 & 750 & 20 & $\mathrm{Ar} / \mathrm{H}_{2}$ \\
\hline Sample E & 2 & $>100$ & 750 & 20 & $\mathrm{Ar} / \mathrm{H}_{2}$ \\
\hline
\end{tabular}

TABLE I. FePt sample list, with as-deposited composition of $\mathrm{Fe}_{50} \mathrm{Pt}_{50}$.
$\mathrm{Fe}+\mathrm{H}_{2} \mathrm{O} \leftrightarrow \mathrm{FeO}+\mathrm{H}_{2}$.

Quantitative thermodynamic calculations using the data from Ref. 7 suggest that a ratio of $\mathrm{H}_{2}$ partial pressure to that of $\mathrm{H}_{2} \mathrm{O}$ between 1.0 and 2.4 should be maintained to prevent both silicide formation [reactions (1) and (2)] and oxide formation [reaction (3)]. Higher $\mathrm{H}_{2}$ partial pressure favors the formation of iron silicide, while a lower $\mathrm{H}_{2}$ partial pressure favors iron oxide formation. The possible reactions in our real FePt nanoparticle/substrate system are much more complex than allowed for by the simple model above. However, the ratio of $\mathrm{H}_{2} / \mathrm{H}_{2} \mathrm{O}$ calculated should represent a value appropriate for minimizing reactions between the nanoparticles and the substrate. For an annealing gas of $\mathrm{Ar}+3 \% \mathrm{H}_{2}$ gas at $1 \mathrm{~atm}$, the desired range of $\mathrm{H}_{2} \mathrm{O}$ partial pressure conveniently corresponds to the saturated vapor pressure of $\mathrm{H}_{2} \mathrm{O}$ between 25 and $13{ }^{\circ} \mathrm{C}$. Thus, a suitable $\mathrm{H}_{2} / \mathrm{H}_{2} \mathrm{O}$ partial pressure ratio is readily obtained by the use of a roomtemperature water bubbler.

We have used both controlled and uncontrolled reducing gas annealing in our laboratory for a variety of investigations of FePt nanoparticles and report here on the characterization of five samples (identified as A, B, C, D, and E) by analytical TEM. The nominal FePt deposit thicknesses, $\mathrm{SiO}_{2}$ membrane layer thicknesses, and annealing conditions for these samples are listed in Table I. The samples were analyzed using a Tecnai F30 TEM. Its energy dispersive x-ray (EDX) detector was used to determine the compositions of individual particles, and another detector, high-angle annular dark field (HAADF), was used for $Z$-contrast images.

\section{RESULTS AND DISCUSSION}

Figure 1 shows the HAADF image and EDX spectrum of the as-deposited 4-nm-thick $\mathrm{Fe}_{50} \mathrm{Pt}_{50}$ thin film (sample A). The integrated intensities of $\mathrm{Fe} K_{\alpha}$ and $\mathrm{Pt} L_{\alpha}$ peaks were used to determine the $K$ factor of these two elements according to Cliff-Lorimer equation, ${ }^{8}$ which gives a value of
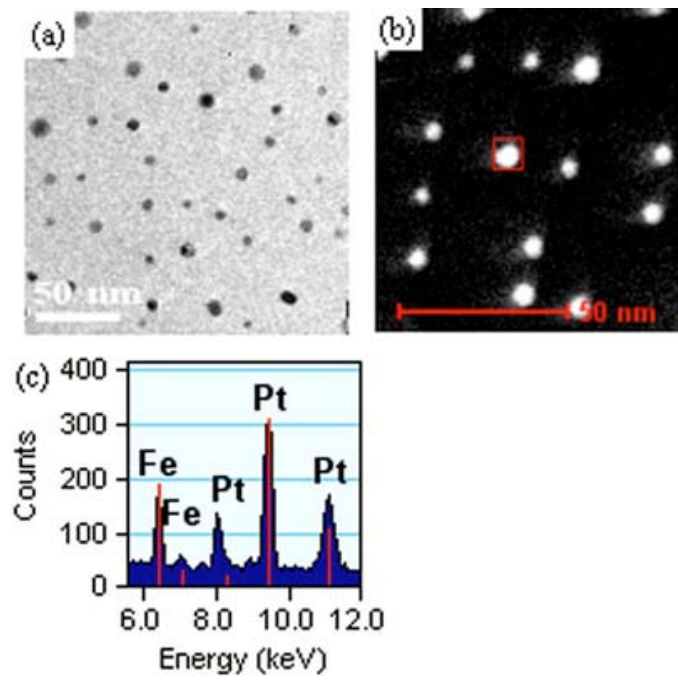

FIG. 2. TEM image and EDX spectrum of indicated individual FePt nanoparticle for sample B. 

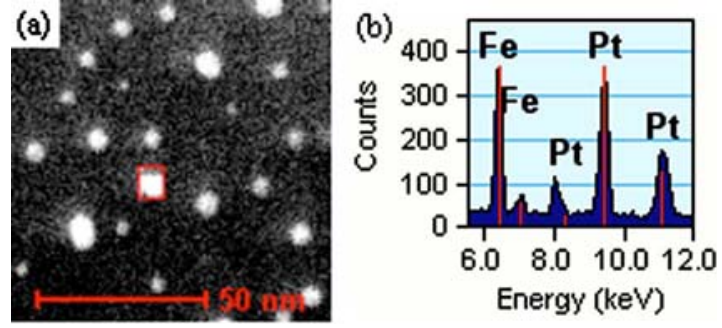

FIG. 3. TEM image and EDX spectrum of indicated individual FePt nanoparticle for sample $\mathrm{C}$.

$1.226 \pm 0.007$. Based on this reference value, compositions of individual nanoparticles in annealed samples can be estimated from the corresponding EDX spectra.

The TEM images and EDX spectrum of FePt nanoparticles of sample $\mathrm{B}$, a 0.25 -nm-thick $\mathrm{Fe}_{50} \mathrm{Pt}_{50}$ thin film annealed in an uncontrolled reducing gas flow, are shown in Fig. 2. Well-isolated particles were achieved, as illustrated by Figs. 2(a) and 2(b). A typical EDX spectrum of one individual nanoparticle is exhibited in Fig. 2(c). The data fit results give a composition of $\mathrm{Fe}_{33} \mathrm{Pt}_{67}$, with uncertainties of \pm 5 at. $\%$ for $\mathrm{Fe}$ and \pm 6 at. $\%$ for $\mathrm{Pt}$, respectively. More than ten particles with different sizes were examined. The compositions ranged from $\mathrm{Fe}_{24} \mathrm{Pt}_{76}$ to $\mathrm{Fe}_{51} \mathrm{Pt}_{49}$, with an average value of $\mathrm{Fe}_{32} \mathrm{Pt}_{68}$, and standard deviation of 9 at. \% for both $\mathrm{Fe}$ and Pt.

To prevent the formation of iron silicides and oxides, annealing in a controlled reducing gas flow was performed on sample $\mathrm{C}$, which was prepared in the same deposition experiment as sample B. Its HAADF image and a typical EDX spectrum are shown in Fig. 3. The data fit gives a composition of $\mathrm{Fe}_{51} \mathrm{Pt}_{49}$, with uncertainties of \pm 4 at. $\%$ for $\mathrm{Fe}$ and \pm 4 at. $\%$ for Pt. The range of compositions was found from $\mathrm{Fe}_{47} \mathrm{Pt}_{53}$ to $\mathrm{Fe}_{52} \mathrm{Pt}_{48}$ with an average value of $\mathrm{Fe}_{51} \mathrm{Pt}_{49}$, and a standard value of 2.1 at. \% for both Fe and Pt.

To determine the mechanisms responsible for the loss of Fe during annealing in an uncontrolled reducing gas, an 8-nm-thick FePt film (sample D) was annealed under the same condition as sample B. The appearance of Fe-rich precipitates in the $\mathrm{SiO}_{2} / \mathrm{Si}$ substrate layer, as shown in Fig. 4, suggested that the diffusion of Fe and chemical reaction of Fe with $\mathrm{SiO}_{2} / \mathrm{Si}$ substrate can be considered as a likely mechanism for the loss of Fe from the FePt nanoparticles.

To examine the influence of $\mathrm{SiO}_{2}$ thickness on the $\mathrm{FePt}$ composition stability, $2 \mathrm{~nm}$ FePt was deposited on a very thick $\mathrm{SiO}_{2}(>100 \mathrm{~nm})$ layer and was annealed in an uncontrolled reducing gas flow (sample E). In comparison to sample B, a similar loss of Fe was not detected in sample E. According to thermodynamic calculations, it is possible that Fe will react directly with $\mathrm{SiO}_{2}$ in the presence of $\mathrm{H}_{2}$ during high-temperature annealing. However, the reaction may be kinetically unfavorable due to a very low diffusivity or solubility of $\mathrm{Fe}$ in $\mathrm{SiO}_{2}$.

\section{CONCLUSIONS}

The loss of $\mathrm{Fe}$ due to oxidation or diffusion into the substrate can prevent the successful preparation of well-

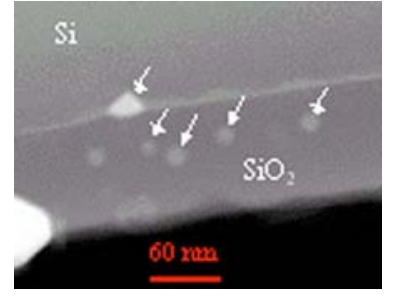

FIG. 4. Fe-rich precipitates (indicated by the arrows) appeared in $\mathrm{SiO}_{2} / \mathrm{Si}$ substrate for sample D.

ordered, stoichiometric, FePt nanoparticles. In this work we report the composition changes observed for small $(<10 \mathrm{~nm}) \mathrm{FePt}$ nanoparticles on thermally grown $\mathrm{SiO}_{2}$ layers on $\mathrm{Si}$ wafer substrates. For nanoparticles prepared on thin $(31 \mathrm{~nm}) \mathrm{SiO}_{2}$ layers, a loss of $\mathrm{Fe}$ during annealing at $750{ }^{\circ} \mathrm{C}$ in $\mathrm{Ar}+3 \% \mathrm{H}_{2}$ was observed by analytical transmission electron microscopy (TEM). Probable factors contributing to this composition change were carefully examined. It was found that diffusions and chemical reactions of $\mathrm{Fe}$ and $\mathrm{Si} / \mathrm{SiO}_{2}$ substrates may be responsible for this change. A similar loss for nanoparticles on thicker $(>100 \mathrm{~nm}) \mathrm{SiO}_{2}$ was not detected by EDX, but should not be presumed negligible. The diffusion of $\mathrm{Fe}$ across $\mathrm{SiO}_{2}$ was confirmed for a relatively thick $(8 \mathrm{~nm}) \mathrm{FePt}$ deposit on the thinner $\mathrm{SiO}_{2}$ by the observation of iron-rich precipitates within the $\mathrm{Si}$ wafer.

Wet annealing was explored to prevent the loss of $\mathrm{Fe}$ during annealing. Based on thermodynamic considerations, a ratio of $\mathrm{H}_{2}$ partial pressure to that of $\mathrm{H}_{2} \mathrm{O}$ between 1.0 and 2.4 should be maintained. FePt nanoparticles on thin $\mathrm{SiO}_{2}$ $(31 \mathrm{~nm})$ have been so annealed and an improved stability of the stoichiometry was confirmed by analytical TEM. We conclude that the loss of $\mathrm{Fe}$ into $\mathrm{SiO}_{2} / \mathrm{Si}$ is a concern for the compositional stability of single layers of FePt nanoparticles during high-temperature annealing and that control of the annealing gas ambient may improve compositional stability.

\section{ACKNOWLEDGMENTS}

This work was supported by the National Science Foundation Grant No. ECS-0304005. We gratefully acknowledge Brigham Young University's TEM facility and Materials Characterization Facility (MCF) of the Advanced Materials Processing and Analysis Center (AMPAC), University of Central Florida, Orlando, Florida, USA.

${ }^{1}$ A. C. C. Yu, M. Mizuno, Y. Sasaki, and H. Kondo, Appl. Phys. Lett. 85, 6242 (2004)

${ }^{2}$ K. W. Wierman, C. L. Platt, and J. K. Howard, J. Magn. Magn. Mater. 278, 214 (2004).

${ }^{3}$ K. Barmak, J. Kim, K. R. Coffey, M. F. Toney, A. J. Kellock, and J. U. Thiele, J. Appl. Phys. 95, 7501 (2004).

${ }^{4}$ T. Seki, T. Shima, K. Takanashi, Y. Takahashi, E. Matsubara, and K. Hono, Appl. Phys. Lett. 82, 2461 (2003).

${ }^{5}$ T. Thomson, B. D. Terries, M. F. Toney, S. Raoux, J. E. E. Baglin, S. L. Lee, and S. Sun, J. Appl. Phys. 95, 6738 (2004).

${ }^{6}$ K. R. Coffey, M. A. Parker, and J. K. Howard, IEEE Trans. Magn. 31, 2737 (1995)

${ }^{7}$ O. Kubaschewski and C. B. Alcock, Metallurgical Thermo-Chemistry, 5th ed. (Pergamon Press, Oxford, 1979), pp. 268-340.

${ }^{8}$ D. B. Williams and C. B. Carter, Transmission Electron Microscopy (Plenum Press, New York, 1996), pp. 597-620. 